\title{
ATTITUDE AND MOTIVATION OF STUDENTS TOWARDS LEARNING ENGLISH AS SECOND LANGUAGE IN A SECONDARY SCHOOL IN PENANG
}

\author{
Malini Ganapathy and Gooi Chiew Ying \\ Universiti Sains Malaysia
}

\begin{abstract}
Today, the English language as a medium of instruction and communication has become very important and makes an increased contribution to education and efficiencies of the students and enables them to fulfil the major demands of the institutions and organizations they work in. In Malaysian schools, as the language is not taught from the beginning in the schools, many of the students are not able to grasp the language at a later stage in their lives. Due to various factors, the students are not able to gain the right attitude and motivational level, which is essential to learn and use the second language effectively. Thus, there is a need to understand the attitudes and motivational level of the students in a secondary school in Penang to identify the various factors, which influence their attitudes and motivational levels. Using focus group interviews, this qualitative case study is an attempt to understand the views of students about learning ESL and the attitudes they have developed about the language and its use. This study is also an attempt to understand the motivational levels and the reason behind the motivational level which involve 20 students in a secondary school in Penang. The results of the research confirm that students have developed both positive and negative attitudes and motivation towards ESL due to the lack of proper environment and teaching approaches administered.
\end{abstract}

KEYWORDS: ATTITUDE, MOTIVATION, ESL (ENGLISH AS SECOND LANGUAGE), INTEGRATIVE ORIENTATION, SOCIOCULTURAL IDENTITY

\section{Introduction}

English as second language

English is the language which is well-understood and well-recognized in different parts of the world. The need for global communication has been increasing with globalization. This has led to the need for establishing a global language. According to Rhode (2010), English dominates the international politics, business and culture (Musa et al., 2012). Several countries across the world have widely accepted the language and use it in some form and learn the language as a second or third language (Musa et al., 2012). The knowledge of the language enables the people to take advantage of the opportunities in the international market.

English language as a medium of instruction and communication has become very important and makes an increased contribution to education and efficiencies of the students and enables them to fulfil the major demands of the institutions and organizations they work in (Mariadass \& Kashef, 2012, p.130). In Malaysian schools, English is taught as the second language (ESL) which has led to the poor 


\section{ATTITUDE AND MOTIVATION OF STUDENTS TOWARDS LEARNING ENGLISH AS A SECOND LANGUAGE IN A SECONDARY SCHOOL IN PENANG}

performance of the students as they move from primary to secondary school where they learn a few of the subjects in English (Mariadass \& Kashef, 2012). As the language is not taught from the beginning in the schools, many of the students are not able to grasp the language at a later stage in their lives.

The Malaysian Ministry of Education developed a National Education Blueprint in order to bring effective changes in the education system, which will prepare the children in a manner that they would be capable of different international level challenges (Ministry of Education, 2012). The Blueprint focuses on understanding current performances and challenges, establishing clear vision and aspirations and outlining comprehensive transformation programme for the system (Ministry of Education, 2012). To ensure that the students get enough knowledge and skills in the school which will enable them to compete at international level in the future, the educational system has taken a holistic approach wherein the child has to be developed along spiritual, intellectual, emotional and physical level (Ministry of Education, 2012). To become competitive at an international level, the educational institutions have been working on promoting effective learning of English as a second language.

This study aims to identify the factors influencing the attitude and motivational levels of the secondary level students in different national schools in Penang which will enable the researcher and the schools to improvise their teaching approach and create a more positive attitude and increased motivation among secondary students. The research would enable identification of the changes in various aspects, which will help the students to learn the language more proficiently, which will help them boost their performance in their present and tertiary education.

English has become the most important language and means of instruction and communication across the globe. The language allows the students to choose different career options and have better opportunities for career growth. The students are expected to learn the English language effectively as the subjects such as science, business, mathematics and social studies are taught in English. English as a secondary language in Malaysia has caused major problems to students in understanding the use of language, and also has made writing, a difficult task for the students in the secondary school classrooms (Hiew, 2012).

English is considered as an important language in Malaysia but the lack of effective environment has led to difficulties in understanding word meanings and implications (Mariadass \& Kashef, 2012). As English is a second language, there are various factors which influence the learning process of the students' learning in the school. The factors can include motivation, attitude, learning methods, perceptions, curriculum and lesson plan, teaching methods and approaches (Hiew, 2012). The attitude and motivation of the students are found to be the two main factors, which influence the success of the students in learning English as the second language. As mentioned above in the study, that English is considered as the second language in the country, Malaysia since it has been found that there exists a deficiency level in the proficiency of the students. It is assumed to be evident from the above study that the attitude and behaviour of every Malaysian student towards learning English has been declined in most schools. Though, it is considered as one of the most inspiring opportunities for career growth, the performance level is constantly decreasing at an alarming rate (Hashim \& Leitner, 2016). There is a need of emergence to introduce English as the main subject in Primary schools so that the demand of such languages may inherit the level of education in maximum Malaysian schools sector. The entire assignment prefaces with the learning attitudes and behaviours of Malaysian students towards learning English as the main subject (Van der Walt, 2013). The upcoming future environment of maximum Malaysian schools is improving its atmosphere to make a perfect enlargement to learn English as the core subject. It is essential to develop English in the primary sector of schools so that the base of students must be expanding with greater flexibility. All around the word, English is considered as one of the most important languages, as a means of instruction and communication to choose varieties of 


\section{ATTITUDE AND MOTIVATION OF STUDENTS TOWARDS LEARNING ENGLISH AS A SECOND LANGUAGE IN A SECONDARY SCHOOL IN PENANG}

career opportunities. Being a second language in most of the Malaysian schools, it has led most of the students to face difficulties in achieving higher potential growth in the understanding of the use of language. The schools in Penang operate under the national school system with a uniform curriculum (Hiew, 2012).

At the primary level, the local language of Malay is used as a language of instruction and in the secondary level; Malay language is used as the primary language for teaching all subjects except English, Science and Mathematics, which makes learning English language effectively very important for the students at the secondary level (Choy \& Troudi, 2006). It enables the students to gain good command over the English language and prepare for tertiary education. It has become very essential for the students in secondary schools to learn English effectively so that they can perform well in mathematics and science and also gain the ability to perform well in their tertiary level education. As English is introduced only at the secondary level, the students face difficulties in acquiring the language due to various factors. There is a need to understand the attitude and motivation of the students towards learning English as the second language to improve the student's abilities to learn the language. Besides, there is a need for understanding the learner's views and experiences in learning the second language to identify the difficulties and barriers encountered in the classrooms and in their external environment. This research aims to analyse the various factors including the attitude and motivation of the students towards learning English as the Second language. There is also a need to study the attitude and motivation of Penang's secondary school students in order to bring effective changes in the teaching approaches, attitudes of the students and enhance the motivational level of the students to learn the language effectively. The need for understanding the various aspects which influence the students learning process is essential to overcome the barriers and provide the students an effective environment, required resources and develop the necessary attitudes and motivation among the students in the secondary school in Penang.

\section{Significance of the study}

English has become an important language for the students in Penang and across Malaysia, since the students learn the subjects in English once they move to secondary school (Hiew, 2012). English language has been adopted by the schools and universities in Malaysia since past few decades and the students are required to be proficient in the language to continue their secondary and tertiary education (Choy \& Troudi, 2006). It has become very important for students to learn this language effectively in the secondary schools in order to be able to choose the desired courses and career in the future. Currently, ESL in the national schools is taught only from the secondary level and at primary level the students study different subjects since the local language, Bahasa Malaysia is the official language (Hiew, 2012). This makes it difficult for the students to predominate the new language as they move to the secondary level from primary due to various factors. The motivational levels of the students vary to a great extent across the schools in Penang in relation to learning ESL.

Due to various factors, the students are not able to gain the right attitude and motivational level, which is essential to learn and use the second language effectively. Thus, there is a need to understand the attitudes and motivational level of the students of secondary schools in Penang to identify the various factors, which influence their attitudes and motivational levels. This study is an attempt to understand the views of students about ESL and the attitude they have developed about the language and its use. The study is also an attempt to understand the motivational levels and the reason behind the motivational level, which will help in understanding the students' approach and efforts towards learning ESL. The significance of this study is that it will enable the researcher to identify the various 


\section{ATTITUDE AND MOTIVATION OF STUDENTS TOWARDS LEARNING ENGLISH AS A SECOND LANGUAGE IN A SECONDARY SCHOOL IN PENANG}

factors, which influence attitude and motivational level of the students and the teachers about the ESL in order to bring changes in the teaching approach.

\section{Literature review}

\section{Student's Attitudes in Learning ESL}

Attitude can be defined as expression of like or dislike towards a place, person, event or thing. Attitude of a person enables one to identify some of the other person's characteristics. An attitude has three components, which include affective, behavioural and cognitive. Affective is a component, which refers to emotional reaction a person has towards an object or a person. It refers to an attitude developed due to emotional reaction, which comes mainly from a person's value. The behavioural component refers to the way a person behaves towards the attitude object. It is the manner in which a person behaves in response to a certain thing or event. The third component of cognitive refers to beliefs and thoughts about an attitude object. The cognitive attitude develops in four steps, which include: connecting the previous knowledge and the new one, creating new knowledge, analysing new knowledge and applying new knowledge in many situations (Kannan, 2009). In learning and development, it is very essential that the students have a positive attitude and perception about the tasks they carry out and the subject they learn. The two types of attitude which affect the learning process of students include: attitude about learning climate and attitude about classroom tasks. According to Fisher (1985), the role of classroom climate is very important in the learning process. The climate is conceptualized in terms of factors such as quantity and quality of the resources available, physical environment of the class and acceptance by the teachers in the class along with other factors (Mariadass \& Kashef, 2012).

The learning styles also influence the student's attitude towards the learning process. Attitude of a student is determined by his/her beliefs about the outcomes or attributes of carrying out a task, which are evaluated at a later stage (Musa et al., 2012). Learning is an emotional process and students and teachers get involved in various activities (Musa et al., 2012). Attitude enables the learners to express the objects they like or dislike with respect to certain situations. According to Troudi (2006), the emotions and inner feelings influence the attitude of the person in the target. English has become one of the main subjects for every student to become competent (Kannan, 2009). Learning a language is related to the attitude the students develop towards the languages. According to Karahan (2007), positive language attitude enables the students develop positive orientation towards learning English (Musa et al., 2012). If the student develops a negative attitude towards learning the English language the efforts of the teachers to simplify the language will not enable the learner to understand or learn the language effectively (Oroujlou \& Vahedi, 2011). According to Levine (2003), the students have different attitude towards the first language and the subject they study as second language (Kannan, 2009).

But the students cannot develop similar attitude for second language as they have more exposure to it only in the classroom and once they are out they do not have an environment where they can further develop the language (Musa et al., 2012). According to Gardner (2004), a student having favourable attitude towards learning English language but is not motivated to learn will not succeed in learning the language (Mackey \& Gass, 2015). The student will also be unable to learn the language if he/she is highly motivated but does not have the favourable attitude.

Student's motivation in learning ESL 


\section{ATTITUDE AND MOTIVATION OF STUDENTS TOWARDS LEARNING ENGLISH AS A SECOND LANGUAGE IN A SECONDARY SCHOOL IN PENANG}

Motivation can be defined as the process, which initiates, guides and maintains goal-oriented behaviours and actions (Mahadi \& Jafari, 2012). It represents an individual's desires, actions and needs. Motivation is essential while learning a second language. The students who are motivated always develop a positive attitude towards learning English (Musa et al., 2012). According to one of the studies conducted by Racha (2003) in a secondary school, which was aimed at assessing the readiness of the students learning mathematics in English, showed that many of the students had a positive attitude and were highly motivated to learn the subject in English since they found it challenging (Musa et al., 2012). The students who were less proficient were not very confident and comfortable in learning the language. It was found that even if they had a positive attitude they lacked motivation due to lack of confidence and abilities to learn the new language (Mahadi \& Jafari, 2012). Motivation can be categorized in to intrinsic and extrinsic. The intrinsic motivation refers to the personal desire of the individual to carry out a task and is associated with integrative orientation (Mackey \& Gass, 2015). When students are internally motivated they do not need any external reward or motivation to perform a task. The extrinsic motivation is associated with instrumental orientation and the learner develops desire to learn the language to get an external reward.

According to Gardner (1985), the students having intrinsic motivation learn to interact with the community or find approaches to learn the language effectively whereas the extrinsic motivators who are instrumentally oriented, learn the language for practical goals (Kannan, 2009). In one of the study carried out among the Malaysian students in different universities it was found that some students learn English as a second language for their career and to fulfil the graduation requirements whereas, others learn out of their own interest and desire and enhance their knowledge about other culture and as they need it while travelling to different nations (Hiew, 2012).

The other main factor which can de-motivate the students to learn the language is lack of effective environment, as the students lack the access to environments where others speak the same language (Hiew, 2012). The students get an opportunity to speak and learn only at the school and once they are out of the school they do not get very less opportunity to use the language while conversing with others and hence, have limitation in their exposure to the target language (Mariadass \& Kashef, 2012). This reduces their motivation even though they have a positive attitude about the language. The physical environment, teacher support and lack of required resources also influence the motivational levels of the students towards learning English as the second language (Musa et al., 2012).

\section{Socio-Educational Model}

Motivation and the positive attitude are very essential for the students to learn the second language effectively. One of the models which depict the attitudes and motivation in second language learning was developed by Gardner in 1960s (Oroujlou \& Vahedi, 2011). According to Gardner, the second language acquisition is carried out in different contexts and he believes that the nature of context is the first thing to be considered (Gardner, 2006). He emphasizes that learner's cultural environment also has significant impacts in the process of acquiring another language and can act as one of the factors motivating the learning of the language (Oroujlou \& Vahedi, 2011).

Figure 1: Socio-Educational Model 


\section{ATTITUDE AND MOTIVATION OF STUDENTS TOWARDS LEARNING ENGLISH AS A SECOND LANGUAGE IN A SECONDARY SCHOOL IN PENANG}

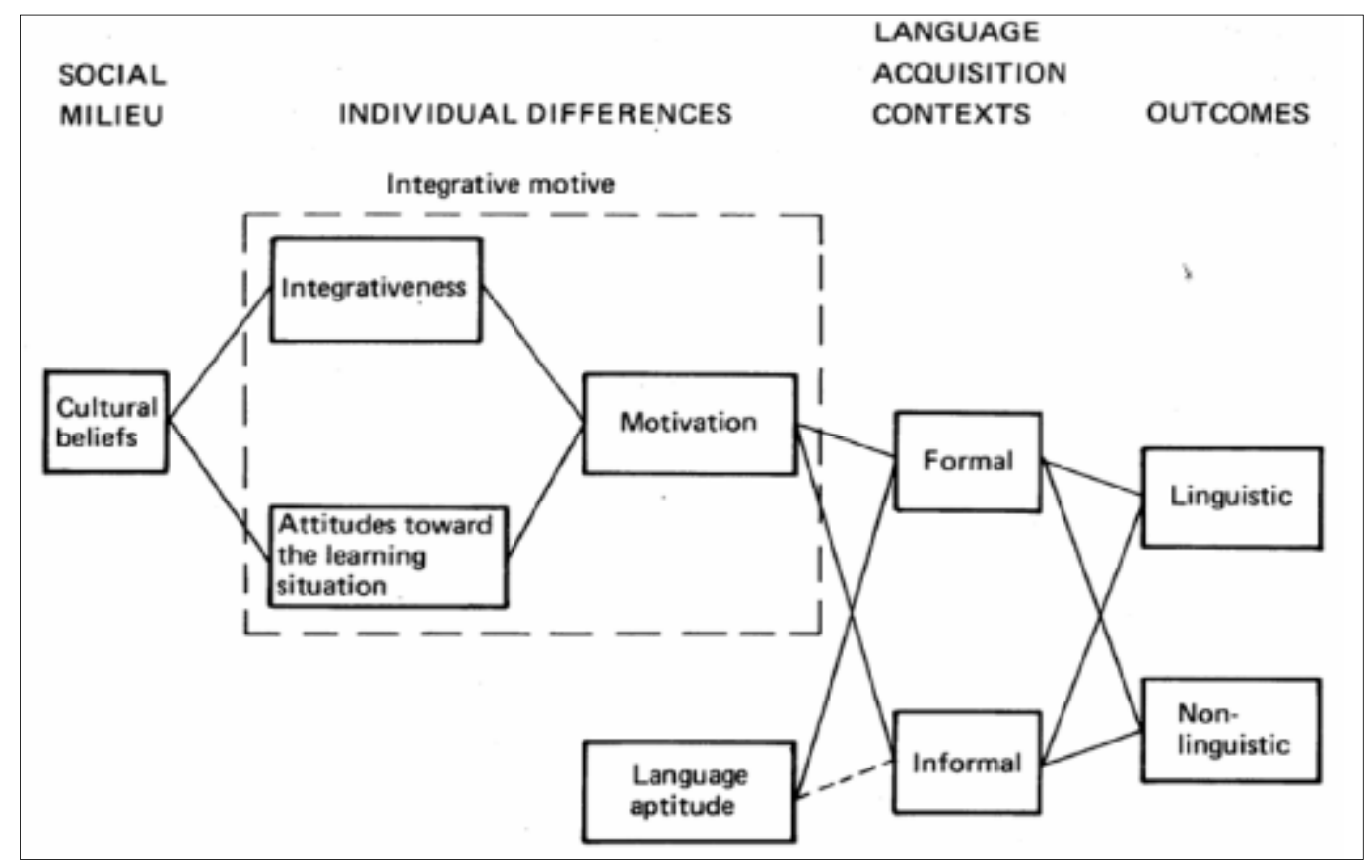

Source: Adopted from Gardner, 2006

The model includes four variables, which are interrelated and are essential for learning the second language and the variables are: individual's culture and environment, individual differences having sub variables of aptitude, motivation and intelligence and anxiety, the third variable is settings, where language is being learnt and outcomes such as linguistic knowledge and language skills (Mahadi \& Jafari, 2012). He has at a later stage added the concept of integrative motive as a variable under individual differences (Gardner, 2006). He believes that students learn new languages based on the ir interests in identifying second language community and their beliefs, culture, and attitude towards the learning situation, the physical environment, response to the textbooks, evaluation of the abilities of language teachers and the language course (Oroujlou \& Vahedi, 2011). The learning situation nature influences student's motivation to a great extent. If the teacher teaching the language is interesting and skilled having a good command of the English language, the students look forward to learning the language with greater interest. The school's efforts to develop an exciting curriculum, carefully construct the plans to teach the lessons and effective evaluation procedures will enable the teachers to promote higher levels of motivation among the students (Mahadi \& Jafari, 2012).

According to Lamb (2004), the integrative motivation is found to be less among the students where learners have limited contact with the second language speakers and their culture and the learners are not able to go beyond a certain level of learning, understanding and practice of the language (Schafer, 2008). Lambert \& Gardner (1959) states that motivational levels differ while learning ESL, as language is inherently related to socio-cultural identities and socio-political factors (Mahadi \& Jafari, 2012). In the socio-educational model, motivation to learn a second language plays an important role as there are various factors, which influence the learner (Gardner, 2006). The model states that the motivation is evaluated in terms of three components, which include: The desire to learn the language, attitude towards learning the language and motivational intensity (Taie \& Afshari, 2015). Burdens (1977) consider language as a part of one's identity and a means to convey one's identity to other people 


\section{ATTITUDE AND MOTIVATION OF STUDENTS TOWARDS LEARNING ENGLISH AS A SECOND LANGUAGE IN A SECONDARY SCHOOL IN PENANG}

(Schafer, 2008). The acquisition of a second language is more than just learning about new information. It is a process wherein the learners acquire certain elements, which are symbolic to the ethno linguistic community (Taie \& Afshari, 2015). The learners or students have to acquire new words, pronunciation, and grammar and learn the new concepts, new ways of saying different things and new words order, which together will enable the learners to acquire knowledge about the new language effectively (Mariadass \& Kashef, 2012).

Gardner's model has since its development and evolvement, focuses on six latent constructs, which include: aptitude of the language, motivation, attitude towards learning situation, integrativeness, language anxiety and language achievement (Taie \& Afshari, 2015). The learning situation has to be conducive for the learners to be able to understand the new aspects of the language (Schafer, 2008). The learners should have professional teachers having sound knowledge and command over the language, which would enable them to use different approaches in teaching based on the understanding levels of the learners (Venugopal, 2005). The language achievement and anxiety is related to the attitude of the learners, which they develop based on the earlier discussed components of affective, behavioural and cognitive abilities of the learner. Kumaravadivelu (2006) also emphasizes that language learning also depends on the social and political forces of power and domination impact on the use and structure of the language (Taie \& Afshari, 2015).

As discussed earlier, there is a need for intrinsic motivation to the learners, which can be provided by creating conducive environments and providing opportunities to the learner by providing the required resources such as books, curriculum and teaching approach. Attitude and motivation among the learners can be developed by creating a good environment for the learners or students and developing different approaches to develop the language skills (Taie \& Afshari, 2015). The institutions need to identify and measure the characteristics of successful language learner and improve the process of language teaching. There is also a need for the learners to develop or possess cultural flexibility, wherein, the learners identify the cultural constraints and avoid getting influenced by them. The learners are also required to achieve tolerance for ambiguity wherein the learners should identify the multiple possibilities, which enable them to interpret the language effectively.

\section{Relevant past studies}

English language is found to be difficult when taught in a non-native English speaking country. It is difficult to learn English language in a context where it is not spoken outside the classroom. Several researchers have found motivation and attitude of the students to be playing a major role towards effective learning of English as second language.

One of the researches analysing the impacts of motivation on English language learning was carried out by Fadel Othman and Khaed Shuqair. The study was conducted to analyse the motivational level of students in the Gulf States. The research was carried out based on secondary sources, which in turn depended on primary sources such as case studies, observation and empirical research (Othman and Shuqair, 2013). The research highlighted the lack of motivation among the students in Gulf States towards learning English language due to the increased influence of their culture and integration of the local language strongly within the communities (Othman and Shuqair, 2013). It was also found that the approach of learners and teachers was unenthusiastic towards learning English as second language.

Ghenghesh carried out a research in Tripoli areas International school where students learn English as second language to assess the factors, which influence the motivational level of the students towards learning the language (Ghenggesh, 2010). The research has a mixed research approach wherein the interviews of teachers were carried out and students were surveyed. The research highlighted that the 


\section{ATTITUDE AND MOTIVATION OF STUDENTS TOWARDS LEARNING ENGLISH AS A SECOND LANGUAGE IN A SECONDARY SCHOOL IN PENANG}

motivational level reduces with the age of the students (Ghenggesh, 2010). The research also highlighted that the motivational level reduces due to lack of required context and due to lack of exposure to native-English speaking people (Ghenggesh, 2010).

Another study carried out by Larsson and Olsson in the Swedish secondary schools was aimed at assessing the impact of cultural background on attitude of the students learning English as second language (Larsson and Olsson, 2008). The study was carried out in two schools among the students studying in year nine and who belonged to different degree of multiculturalism. The results of the research highlighted that most of the students irrespective of their cultural background believed that English language will prove to be of great benefit in the future as they have a positive learning environment, which has led to development of positive attitude about learning environment (Larsson and Olsson, 2008).

\section{Method}

\section{Research process}

The researcher chooses the school from which the participants will be chosen for the research. The researcher chooses School A in Penang for carrying out the research. The research process was carried out over a period of 8 weeks. The researcher selected the sample from the school after taking permission from the authorities and following all the ethical procedures. The researcher chose 20 students from the school as the participants for the study. They were willing to participate voluntarily for the study. The sample has equal number of male and female students, which will enable the researcher to assess the attitude and motivation of the students based on their gender. The researcher used focus group interview as the data collection method due to insufficient time and as it will enable the researcher to acquire the information based on the spontaneous responses of the students rather than biased responses. The interview was carried out in 4 sessions. The interview helped the researcher to identify the different perspectives of the students about English as the second language and identify the factors, which influenced their attitude and motivation towards learning the language. The collected data was analysed after it was transcribed and based on the analysis, recommendations were proposed to bring positive attitude and increase the motivational levels among the students.

\section{Research method}

This research is carried out based on a case study research method due to the lack of time and difficulty in getting access to more number of students. Case study is an approach wherein the researcher focuses on gaining increased understanding of a particular event or phenomenon (Emmel, 2013). Case study helps in understanding a complex and ongoing issue, which is already known and allows contextual analysis of limited events or conditions and their relationships (Emmel, 2013). In this approach the researcher starts with the research questions, which helps the researcher to look for evidence and determine the method of analysis to be used in carrying out the study. The case study approach was used for this research as the issue was real and known. Also, the contextual analysis would help in understanding the situation better and in order to find effective solutions to solve it.

\section{The Sample}




\section{ATTITUDE AND MOTIVATION OF STUDENTS TOWARDS LEARNING ENGLISH AS A SECOND LANGUAGE IN A SECONDARY SCHOOL IN PENANG}

\section{Students}

The participants for this research are 20 students of School A, Penang. English is the language of their instruction in the school. The school has students coming from different cultural background and with different levels of learning abilities. The participants were randomly selected divided along equal gender lines with 10 male and 10 female. The participants were also of different age and learning capabilities which sprung from their different levels of exposure. This helps in gathering information about the different perspectives of the students about learning English language which affect their attitude and motivation. The participants for this research study ESL and do have access to the same books and other study materials, but have more than one teacher teaching the language and have access to other resources outside and inside the school, which are accessed based on the students' willingness to learn the subject. This also helps in analysing their attitude and motivation towards learning the subject. Because of ethical reasons, the anonymity of the students was maintained, therefore, students from each focus group will be labelled as A and the focus group session will be numbered accordingly; A: FG1.

\section{Sample size}

The sample size for this research is 20 due to the difficulty in gaining access to the participants in the given timeframe. The sample size is small to avoid any delays in completing the research and the emphasis is given more on collecting the correct and appropriate information needed to answer the questions and to analyse the data effectively, which helped in gaining information on the different factors influencing the attitude and motivation of the secondary students in the school. The participants are 10 male students and 10 female students, to analyse the different perspectives about learning English as second language. As discussed earlier, gender, attitude, motivation and perspective differ between the male and female students due to the differences in their cognitive abilities. The sample size chosen is small as the main factors for developing the attitude and motivation would be similar with little variation yet they cannot be fully generalised.

\section{Sampling technique}

The sampling technique used in this research is random purposeful sampling. In this technique the samples can either be stratified or chosen based on particular cases, which vary according to a key dimension (Ellis, 2010). The participants chosen under such technique offer increased information to the researchers (Emmel, 2013). This technique enables the researchers to gain increased information form the specifically chosen population and gives them ability to make effective interferences (Ellis, 2010). It is a non-probability technique and uses only small sample size (Flick, 2015). The main purpose of this technique is to focus on certain characteristics of the participants, which helps in answering the research questions (Flick, 2015). The researcher has chosen this sampling technique as she is analysing the attitudes and motivational level of the students in the secondary school as it is believed that it directly influences the ability of the students to learn the language. In this sampling technique, the participants chosen belong to the same context of learning English as second language and highlight their perception, attitude and motivation towards learning the language. This technique emphasizes on the credibility of the information rather than generalizing it. This sampling technique would allow the researcher to assess how the students develop different attitude and motivation in the same context.

\section{Research instruments}




\section{ATTITUDE AND MOTIVATION OF STUDENTS TOWARDS LEARNING ENGLISH AS A SECOND LANGUAGE IN A SECONDARY SCHOOL IN PENANG}

The research instrument used in this research is a focus group interview. In this qualitative research approach, group of people are asked about their opinions, perceptions and attitude towards a certain event, context or idea (Marshall and Rossman, 2010). The focus group interviews include discussions related to the research topic and the information and opinion of the participants is observed and recorded by the researcher, which is later analysed to arrive at a conclusion (Mackey and Gass, 2015). This data collection method was used since it enables the researcher to collect the real views and responses of the participants as the participants respond spontaneously and the participants tend to elaborate their responses rather than providing biased answers (Seidman, 2012). This research approach allows researcher to probe the participants further based on the responses of the different participants and gain in-depth information of the research topic (Seidman, 2012).

The interview include semi-structured questions, which enable the researcher to form new questions and gain information from the participants. The interviews were carried out by the researcher and were done in group of 5, which allowed every participant to put their views about learning English as second language. It allowed the researcher to observe the attitude of each participant and also learn about their motivational level for learning the language. The researcher asked open-ended questions and allowed the participants to express their views freely and not limited the interview to specific and routine questions. The focus group interviews enabled researcher to gather more information and analyse the research topic from a broader perspective and was able to observe the actual responses of the students without being influenced by situation or people. The researcher chooses certain areas based on the responses and probed the participants further. The researcher did bring some variation in the questions asked in the interview but they were aimed at gaining more information about the research topic. The interview time was not fixed, which allowed the participants to freely discuss the topic. The researcher scheduled the focus group interviews when the time was convenient for the participants and written consent was taken from the parents of the students. The researcher recorded the interviews and chalked out and organized all the relevant information for it to be analysed.

\section{Data Analysis}

The researcher collected increased data which included the opinions and suggestions about the research topic. The analysis of this information enabled researcher to draw conclusion on the attitude and motivation of the participants and the measures which can be taken to develop positive attitude and motivation among the secondary school students of School A in Penang. The transcript of the recorded information was created and analysis of the information was done based on the grounded theory, which is developed from the data collected and analysed. The process of analysis of the data starts from the time the researcher begins to collect data (Charmaz, 2014), the information when the data was collected and transcribed, then the indexing of data was finally carried out. In this analytical approach, series of concepts or categories were developed, which help in explaining the phenomena emerging from the study. It is a dynamic process and as the data is collected, the concepts are re-visited and the relationship between the categories was established (Charmaz, 2014). This approach was used to the analyse data so that the students can be categorised based on the factors influencing their attitude and motivation. This enabled the researcher to link them and arrive at a solution to enhance it further. 


\section{ATTITUDE AND MOTIVATION OF STUDENTS TOWARDS LEARNING ENGLISH AS A SECOND LANGUAGE IN A SECONDARY SCHOOL IN PENANG}

\section{Result \\ Report of the assessment of student's attitude and motivation towards learning English as second language}

\section{Attitude of the students towards learning ESL}

In the focus group interviews every group was asked about their attitude towards learning English as second language which was assessed based on their response on how crucial they felt the language was in the secondary school or if they find that the language might not help them in future. Through the interview it was found that most of the members in every group found English as second language important for their future as they aspired to get into professional courses in future for which they believed that language is essential. The students had a positive attitude towards learning the language but few found it difficult due to lack of required resources. One of the students below responded as follows who has a very positive attitude about the language:

"I find the language very interesting and easy to learn as my parents and I speak English for some part of the day and they encourage me to learn few pages of any type of book written in English, which helps me learn new words every day and also learn about the usage of the word in other contexts" (B: FG1)

However, another student has developed a negative attitude towards the language and is learning it as it is compulsory in the school and he does not practice effective ways to learn the language. He highlighted his perspective about the language learning as follows:

"I have not developed an interest for the subject as no one in my house knows the language well and the only time I get to learn to speak the language is in school during the English classes. In the rest of the classes we speak our local language most of the times so I hardly get an opportunity to use the language in a conversation and do not find it essential." (D: FG2)

Besides, very few of the students found that English is not very important for them and can be learnt just as any other language as they just want to learn the basics effectively and use it only during the exams. They are one of the opinions that they would use English in future and did not find it more important than their local language. One of the students commented as follows:

"I have not developed an interest for this language as I might choose courses which require only basic knowledge of English that I am learning right now. However, I do not take much effort in understanding the grammar and punctuation effectively, as I do not feel that it is very important for me." (A: FG4)

On the other hand, few students had indicated that English would help them become more successful in choosing the best careers and it will enable them to travel to other countries for further studies. On the same note, another student in the same group commented that:

"I believe the language is of great importance to choose a professional career as it is a widely used language across the world and to try out different career or learning opportunities one should learn the basics and the usage of the language more effectively". (C: FG4) 


\section{ATTITUDE AND MOTIVATION OF STUDENTS TOWARDS LEARNING ENGLISH AS A SECOND LANGUAGE IN A SECONDARY SCHOOL IN PENANG}

\section{The motivational level of the students towards learning ESL}

The interview involved assessing the motivational levels of the students towards learning English as a second language. It was found that motivation among majority of the students was high as the teacher made the subject quite interesting and gave the homework, which help them to learn the teachings in the school more effectively. One of the students was highly motivated to learn the language as she liked the subject and aimed at studying English literature in the future and their parents speak the language fluently. She highlighted this as follows:

"I find the language interesting and am highly motivated towards learning it as my parents have achieved professional degrees and have found that learning English has provided them with good career options". (C: FG3)

She further added that:

"I have developed interest in English Literature as my mother is a professional writer, which has enabled me to learn the basics and use of language effectively." (C: FG3)

This highlighted that having an effective external environment helps students gain positive attitudes about learning the language and also motivates them to learn the language more effectively.

The motivational level was found less in few students as they found it difficult to grasp the language and hardly used the language in the external environment. Moreover, some students were not able to cope with the teaching in the class and also struggled to complete the homework as they did not have parents who are good in the language. Two other students expressed the same views and they portrayed that:

"I am not too keen in learning this language as I find it difficult to understand and do not have anyone at my home to clear my doubts as my parents do not understand the language to a great extent." (B: FG4) (B: FG2)

One of the students further added that:

"As I do not get anyone to clear my doubts, I find it frustrating and end up learning many things incorrectly, which I realize when I get my exam results". (B: FG4)

This was found to de-motivate the students further. It was found that the school did not provide any extra facilities for such students besides giving more practice homework to such students. One of the students among them expressed that:

"I see the language as a burden as the school does not conduct any extra activities or exercises, which can help students like us who do not have anyone speaking English at home learn the language effectively at school and practice it at home instead teachers provide extra home assignments, which are not of much help as our basic understanding itself is not clear". (B: FG3)

\section{The students' challenges in learning ESL}

The overall views about learning the language as a second language were positive. It is essential for them to learn other subjects taught in English. Most of the students found that English is an essential language for their future studies and had a positive attitude about the language. One student commented that: 


\section{ATTITUDE AND MOTIVATION OF STUDENTS TOWARDS LEARNING ENGLISH AS A SECOND LANGUAGE IN A SECONDARY SCHOOL IN PENANG}

"I have an aim to take professional course in future in international university for which learning English is essential and I also believe that it will provide wider choices of career to choose from". (D: FG1)

Besides, another student commented that:

"I find the language interesting as it enables me to learn about different fields and since it is widely used language will help me make better career choices". (E: FG1)

However, the motivational level varied among the participants. Few students learnt the language as they found it interesting, while few believed that ESL is essential language for further studies and they were learning it to be able to gain knowledge of other subjects and some found it difficult as they were highly de-motivated towards learning the language as they aimed at choosing courses in the future, which might not require increased knowledge of English. One of the students commented as follows:

"I find English language very interesting as the language for me, is easy to learn and expressing things more effectively and it also would provide wider career choices for me in the future”. (A: FG1)

The other student expressed that:

"I am not good at learning languages as I am not good with learning grammar and punctuations which makes it difficult for me to communicate effectively in the language and as I do not like learning languages, I might opt for local courses in arts which might not require me to use the language often". (E: FG3)

\section{Discussion}

\section{Students' attitude}

This case study highlighted that many of the students found the subject interesting but had developed a negative attitude about the language due to lack of proper teaching approaches and resources. The schools made little efforts in making the students realize the significance of the language and hence, many have developed an attitude that, it is just another subject which needs to be cleared. According to a student:

"I am not very keen on learning this subject, as I believe knowing the basics of the language is enough to communicate and since I do not use the language quite often, I do not feel it is necessary for me to learn it effectively at this stage”. (A: FG2)

However, there were few students who had developed a positive attitude about the language as they have access to adequate resources and also have the right environment to develop interest in the subject outside the school. This corroborates to Krashen's principles that classroom teaching helps and is essential for students to receive comprehensible input about various aspects of the language to the students who are not yet at a level to receive them from the real world or have access to the environment where others use that language (Musa et al., 2012). Language acquisition becomes difficult for them if the classroom teaching is inadequate and leads to development of a negative attitude as commented by following student: 


\section{ATTITUDE AND MOTIVATION OF STUDENTS TOWARDS LEARNING ENGLISH AS A SECOND LANGUAGE IN A SECONDARY SCHOOL IN PENANG}

"It is difficult to focus on learning this language as I can learn this language only at school and follow only what has been taught and told in the class and I find it difficult to understand certain things and do not have anyone else to help on it besides, the teacher who has a standard approach". (D: FG4)

The students find the lack of attitude is due to lack of resources and teaching approaches in the school as for many, the school is the only environment where they can learn the language effectively.

\section{Students' motivation and engagement}

The lack of right attitude in most of the students and low motivational levels results in lack of interest towards learning the language effectively. Most of the students just pass the subject with minimum marks as it is one of the compulsory subjects. The students have little access to resources and the teaching process is not effective hence, they are not motivated to learn the English language and do not effectively engage themselves in learning the language effectively. This also concurs with the study of Susanna (2007), where students can be demotivated to learn the language if students' learning style and teachers' teaching approach do not match and if the English course does not relate to student's interest and needs. (Susanna, 2007)

One of the students stated that:

"I am not motivated to learn the language effectively or put efforts in understanding the grammar, punctuations etc. as my basics in the language are not strong and teachers have a very standard approach in explaining the different aspects". (A: FG4)

Another student commented that:

"Even though we have access to some books, which help us learn the language better but teaching the language using practical approach and having some sessions where we have some discussions, or exercises can help motivate us to learn the language more effectively". (C: FG2)

\section{Teaching approaches and availability of resources}

As every individual has different levels of skills, knowledge and abilities, learning a language or a task happens at different level in each individual. Every individual has different cognitive skills and some people learn things easily while others find it difficult to learn things with the same approach as remarked by a student below:

"When I approach the teacher with difficulty in some section of the language they explain it to us but not at the level which I understand, so I understand only part of it and cannot use it in other contexts, which makes me think that the language is tough and I doubt my capabilities leading to negative attitude". (E: FG2)

Through this case study the researcher found that the difference in level of understanding and ability to grasp the language also influences the attitude and motivation of students. The case study helped in understanding that students have developed a negative attitude and are de-motivated towards learning the language as the teaching approach of the school is standardized and the teachers and school do not make any extra efforts or have a different approach for the students who have lesser abilities to learn the language and do not have an external environment where they can learn the language. This finding is in relation to Jafari's study where students tend to lose interest in learning a language when the environment which they study does not provide an atmosphere that is conducive to the students. 


\section{ATTITUDE AND MOTIVATION OF STUDENTS TOWARDS LEARNING ENGLISH AS A SECOND LANGUAGE IN A SECONDARY SCHOOL IN PENANG}

Besides, he further states that students with lesser abilities require more attention and easier way to learn language (Jafari, 2013).

\section{Students ' perceptions of their ESL learning experiences}

The key findings from the focus group interview sessions are that the students feel that the language is interesting but they have not developed the right attitude towards the language, and many feel that it is one additional subject (burden), which needs to be cleared for them to move to the next class. The student's perceptions about learning English as a second language is that the language should be made interesting through certain creative activities, which will make them use the language and learn different things about the language. The school should also conduct certain exercises or workshops where students can use the language to communicate with their peers. That will help them use different words in different contexts. The teachers should also assess the performance of every student and suggest some exercises wherein, they can help the student learn the language according to their capabilities and not at the same levels with others. According to Spolsky (1999), developing intrinsic motivation is very essential for students to develop positive attitude and stay motivated to learning the second language (Oroujlou \& Vahedi, 2011). Intrinsic motivation refers to developing interest and willingness of learners on their own volition in order to carry out a certain tasks (Oroujlou \& Vahedi, 2011). Finegan (2005) states that, when teachers take a comprehensive approach to teaching, wherein, the learning will be not just in the classrooms but in external world as well through exercises, small competitions in the class, extra home assignments then the student will be motivated to learn the language and develop a positive attitude (Jafari, 2013). Likewise, the students expressed that small exercises of writing essays, reading different books, or carrying out certain activities in the class will help them develop a positive attitude and motivate them to learn the language.

\section{Conclusion}

This case study helped in gathering information about the reasons behind differences in attitude and motivation of Malaysian secondary school students towards learning English as Second language. The discussions with the students highlighted that, they need access to more resources and need a comprehensive approach to teaching the language, which can help them learn the language more effectively. The students emphasized that by carrying out different approaches to teaching and providing more resources they will be interested in learning and using the language outside the school. It is recommended that, the teachers should include some exercises, which can help the students having difficulty in learning the language to learn better. This case study helped in understanding the attitudes and motivations of the secondary students towards learning English as a second language. The findings of the research highlighted that, students have developed positive and negative attitude and motivation towards the language due to lack of the proper environment and teaching approaches of the school. As the level of understanding differs from one student to the other, they expect the teaching approaches to vary as well, which will help them feel confident and work towards learning the language with a positive attitude and satay motivated towards learning it which will transpire beyond the four walls of the classroom. 


\section{ATTITUDE AND MOTIVATION OF STUDENTS TOWARDS LEARNING ENGLISH AS A SECOND LANGUAGE IN A SECONDARY SCHOOL IN PENANG}

\section{References}

Charmaz, K (2014). Constructing Grounded Theory, SAGE Publications Ltd

Choy, S \& Troudi, S (2006). An investigation into the changes in perceptions of and attitudes towards learning English in a Malaysian college. International Journal of Teaching and Learning in Higher Education, 18(2): 120-130

Ellis, P (2010). The Essential Guide to Effect Sizes: Statistical Power, Meta-Analysis, and the Interpretation of Research Results, Cambridge University Press

Emmel, N (2013). Sampling and Choosing Cases in Qualitative Research: A Realist Approach, SAGE Publications Ltd

Flick, U (2015), Introducing Research Methodology: A Beginner's Guide to Doing a Research Project, SAGE Publications Ltd

Gardner, R. (2006). The socio-educational model of second language acquisition: a research paradigm. EUROSLA Yearbook, 6: 237-260.

Ghenggesh, P (2010). The Motivation of L2 Learners: Does It Decrease with Age? English Language Teaching 3(1): 128-141

Gomleksiz, M. (2010). An evaluation of students' attitudes toward English language learning in terms of several variables, Procedia - Social and Behavioural Sciences, 9: 913-918

Hashim, A., \& Leitner, G. (2016). 3 English in language education policies and planning in Malaysia. Languages in the Malaysian Education System: Monolingual Strands in Multilingual Settings, 46.

Hiew, W (2012). English language teaching and learning issues in Malaysia: Learners' perceptions via Facebook Dialogue Journal, International Refereed Research Journal, 3(1): $11-19$

Jafari, S (2013), Motivated Learners and Their Success in Learning a Second Language, Theory and Practice in Language Studies, Vol. 3, No. 10, pp. 1913-1918

Kannan, R (2009). Difficulties in learning English as a Second Language, 8(5): 1-4

Kumar, R (2014). Research Methodology: A Step-by-Step Guide for Beginners, SAGE Publications Ltd

Larsson, T \& Olsson, J (2008). Attitudes towards English as a Foreign Language in a Multicultural Context, Malmö Högskola

Mackey, A \& Gass, S (2015), Second Language Research: Methodology and Design, Routledge 


\section{ATTITUDE AND MOTIVATION OF STUDENTS TOWARDS LEARNING ENGLISH AS A SECOND LANGUAGE IN A SECONDARY SCHOOL IN PENANG}

Mahadi, T \& Jafari, S (2012). Motivation, Its Types, and Its Impacts in Language Learning,

International Journal of Business and Social Science, 3(24): 230-235

Mariadass, M \& Kashef, S (2012). Investigating Malaysian ESL Students' Writing Problems on Conventions, Punctuation, and Language Use at Secondary School Level, Journal of Studies in Education, 2(3): 130-143

Marshall, C and Rossman, G. (2010). Designing Qualitative Research. SAGE Publications

Ministry of Education, (2012). Preliminary Report: Malaysia Education Blueprint 2013-2025. Ministry of Education Malaysia

Musa, C, Lie, Y, \& Azman, H. (2012). Exploring English Language Learning and Teaching in Malaysia, Journal of Language Studies. 12(1), 35-51.

Oroujlou, N \& Vahedi, M (2011). Motivation, attitude, and language learning, Procedia -Social and Behavioural Sciences, 29: 994-1000

Othman, F and Shuqair, K (2013). The Impact of Motivation on English Language Learning in the Gulf States, International Journal of Higher Education, 2(4): 123:130

Patton, M (2014).Qualitative Research \& Evaluation Methods: Integrating Theory and Practice. SAGE Publications

Schafer, L (2008). Students attitudes and self-concept in English as a function of rose specific pupil/teacher interpersonal compatibility, San Francisco, California, National association for research in teaching.

Seidman, I (2012). Interviewing as Qualitative Research: A Guide for Researchers in Education and the Social Sciences. Teachers College Press

Susanna, A. (2007). The weak language learner: a study of ways of taking weak language learners into consideration in class. Sweden: Vaxjo University, School of Humanities English, GIX115.

Taie, M \& Afshari, A (2015). A Critical Review on the Socio-educational Model of SLA, Theory and Practice in Language Studies, 5(3): 605-612

Van der Walt, C. (2013). Multilingual higher education: Beyond English medium orientations (Vol. 91). Multilingual Matters.

Venugopal, G (2005). The influence of teacher attitude and expectations on pupils' achievement in English, Experiments in Education, Vol. XXIII, No.1.

Zoghi, M, Kazemi, A and Kalani, A (2013). The Effect of Gender on Language Learning. J Nov . Appl Sci., 2 (S4): 1124-1128 


\section{ATTITUDE AND MOTIVATION OF STUDENTS TOWARDS LEARNING ENGLISH AS A SECOND LANGUAGE IN A SECONDARY SCHOOL IN

\section{Contact Details of Authors:}

Gooi Chiew Ying

Email:

Malini Ganapathy

School of Languages, Literacies and Translation,

Universiti Sains Malaysia, 11800 Penang, Malaysia.

Email: malinik@usm.my

\section{Biodata:}

Gooi Chiew Ying graduated from Wawasan Open University with the Master of Education. She had completed her research topic of Attitude and motivation of students towards learning English as second language in a secondary school in Penang.

Malini Ganapathy (Ph.D) is a lecturer at the School of Languages, Literacies and Translation, Universiti Sains Malaysia, 11800 Penang, Malaysia. Her areas of expertise include Literacies, Teaching and Learning English as a Second Language (TESL), Writing, and Literature in English. She has published in these areas especially in journals and books chapters. Besides that, presented her research at international conferences. She is currently a senior member of the International Economics Development Research Centre (IEDRC) and a member of the Organisation for Research and Policy Development of Higher Education Malaysia (PenDaPat). 